\title{
Germination and seedlings response of bermudagrasses under
}

\section{water submersion}

\author{
M. Giolo ${ }^{3}$, R. Masin ${ }^{1}$, S. Macolino ${ }^{1}$ and A. Onofri ${ }^{2}$ \\ ${ }^{1}$ Department of Agronomy, Food, Natural resources, Animals, and Environment, University of Padova, Legnaro (PD), Italy \\ 2 Department of Agricultural, Food and Environmental Sciences, University of Perugia (PG), Italy \\ ${ }^{3}$ CREA-DC, Research Centre for Plant Protection and Certification, Lonigo (VI), Italy
}

\section{Summary}

Bermudagrass (Cynodon spp.) at the mature stage is quite tolerant of submersion, but little information is available on the effects of submersion on seed germination and seedling development. Five cultivars ('Jackpot', 'La Paloma', 'Transcontinental', 'Yukon', and 'Sunbird') were compared in two experiments conducted in growth chamber and greenhouse. Germination percentage in Petri dishes under 'seed floating' $(0,2,4$, and 6 days) and 'seed submerged' conditions $(0,2,4$, and 6 days) was measured while in the greenhouse four out of five cultivars were also tested, except for 'La Paloma'. Seedlings growth under 0, 2, 4, 6, and 8 days submersion was evaluated. In the lab, the cultivars tested displayed a different response to submersion and floating treatments. 'Jackpot', 'Sunbird', and 'Transcontinental' showed the best tolerance to both floating and submersion conditions. In the greenhouse experiment, bermudagrass seedlings appeared to have short-term resilience to flooding, as long as it is not prolonged. All the cultivars showed good tolerance to submersion during germination, while submersion for 6 and 8 days resulted in a significant increase in the average proportion of yellow seedlings.

Keywords

climate, turfgrass, floating, flooding, hypoxia, seed

\section{Introduction}

The Mediterranean area mainly lies in the so-called transition zone, where it is possible to cultivate both warm- and cool-season grasses. The use of warm-season species has been encouraged over the last decade in the transition zones of Europe to reduce cultural inputs required to maintain turfgrasses (Rimi et al., 2011, 2013a, b; Severmutlu et al., 2011). In comparison to the more traditionally used cool-season species, warm-season species use water more efficiently (Casnoff, 1989; Huang et al., 2008) and have a higher tolerance to drought, traffic and fungal diseases (Puhalla et al., 1999).

Current climate change projections for the Mediterranean area show an increase of extreme weather and climate events over the next years. Med-CORDEX (Coordinated Regional Climate Downscaling Experiment) has elaborated some projections on future climate changes in Italy (Desiato et al., 2015, 2019) that indicate an increasing concentration of more intense and less frequent precipitation events (IPCC, 2014; Medri et al., 2013; Zollo et al., 2016).

\section{Significance of this study}

What is already known on this subject?

- Current climate change projections show an increase in heavy rains, which may cause either flooding or waterlogging. The expected climate change will likely influence the choice of turfgrass species and management practices. Several studies demonstrated that bermudagrass plants are quite tolerant of submersion, even when this is relatively prolonged.

What are the new findings?

- Results demonstrated that bermudagrass has shortterm resilience in the case of flooding. The seed showed moderate tolerance to prolonged floating/ submersion conditions, while seedlings denoted hypoxia symptoms after six days of submersion.

What is the expected impact on horticulture?

- Heavy rains may harm the establishment of bermudagrass turfs. However, little information is available regarding the effects of waterlogging on germination and seedling growth.

Climate change influences turfgrass management practices (De Luca et al., 2008) including species choice. Due to climate changes, warm-season species, and especially bermudagrass, are becoming popular in the transition zones of Europe (Macolino et al., 2016). However, only a few studies have investigated the effect of increased rainfall intensity on early-stage growth of warm-season turf species. Heavy rains may cause either flooding, which can produce partial or total plant submersion, or waterlogging when plants are not submerged but soil pores are saturated (Bailey-Serres et al., 2012; Striker, 2012). Waterlogging and, to a greater extent, submersion, can cause several visible symptoms on plants, especially when they are prolonged, such as reduced photosynthetic activity, abscission of leaves, chlorosis, lower growth of roots and stems (Batzli and Dawson, 1997). Flooding events can be extremely harmful to plants (Bailey-Serres et al., 2012), a decrease in oxygen diffusion rate (ODR), $\mathrm{pH}$, and soil redox potential, and an accumulation of toxic compounds are the most significant effects of rootzone pores saturation (Parent et al., 2008; Voesenek et al., 2006). The oxygen diffusion rate is a significant indicator of the availability of oxygen to plant roots that can restrict seedling emergence (Chesworth, 2008; Neira et al., 2015). Studies by Letey et al. (1966) found that at ODR of $0.15 \mu \mathrm{g} \mathrm{min}^{-2} \mathrm{~cm}^{-1}$ roots growth of bermudagrass (Cynodon spp.) drastically reduced, even if 
this species showed more tolerance to compact soil than dallisgrass (Paspalum dilatatum Poir.) and bahiagrass (Paspalum notatum Flugge). Flooding sharply limits $\mathrm{CO}_{2}$ and light availabilities, which are essential for the photosynthesis process (Jackson and Colmer, 2005); light availability is also limited when heavy rains are associated with soil erosion because soil particles muddy the water (Pedersen et al., 2013). Several studies demonstrated that bermudagrass plants are quite tolerant of submersion, even for an extended period. Wherley et al. (2011) studied the response to soil saturation over 72 days on plant development of two warm-season species: common centipedegrass [Eremochloa ophiuroides (Munro) Hack] and 'Tifway 419' hybrid bermudagrass [Cynodon dactylon (L.) Pers. $\times$ C. transvalensis Burtt Davy].

They found that waterlogging reduced canopy cover by $30 \%$ in both species, but shoot biomass decreased in bermudagrass. Tan et al. (2010) demonstrated that bermudagrass plants could withstand prolonged and deep submersion through lowering their metabolism, increasing carbohydrate reserves and improving anti-oxidative activities of roots, which allow an adaptation to hypoxia and anoxia. Ashraf and Yasmin (1991) compared the mechanism of waterlogging tolerance of kallar grass [Leptochloa fusca (L.) Kunth], a species known for its high tolerance of waterlogging and salinity, mangrove grass [Aeluropus lagopoides (L.) Trin.], and bermudagrass [Cynodon dactylon (L.) Pers.] under three water submersion conditions: 1 . No submersion (control); 2. Intermittent submersion (one-week submersion and then drained for one week); 3. Six weeks continuous submersion. They found a significant reduction of chlorophyll content in all species. At the same time, bermudagrass showed less capacity of oxydising the rhizosphere region, concluding that bermudagrass can be evaluated as relatively sensitive to submersion in comparison with the other species regarded as highly tolerant.

In a recent study, Ye et al. (2015) reported that physiological changes caused by submersion are more limited than those observed as a result of drought stress. Submersion causes growth inhibition as a consequence of a decrease in the metabolism of carbohydrate degradation and energy supply (Huang et al., 2019). The strategy adopted by bermudagrass seems to be oriented towards dormancy and delayed growth, which allows this species to be adaptive to a longterm submerged environment.

Although several studies investigated the effects of waterlogging on plant growth and survival, few of them examined the effects of waterlogging on seed germination and seedling growth. Oxygen at atmospheric levels is usually required for seed germination; however, the response to oxygen varies strongly with species (Bewley et al., 2013). Prolonged immersion progressively increases damage to cell membranes, which instead results in significant inhibition of seedling growth (Ye et al., 2015).

The first stage of the complex phenomenon of germination is imbibition. Germination of bermudagrass in water does not seem to be problematic because water potential $(\Psi)$ is $0 \mathrm{Mpa}$ and, according to the hydro time model, it facilitates seed imbibition (Bradford, 2002). Morinaga (1926) found that bermudagrass germinated better in bottles under $100 \mathrm{~mL}$ of distilled water than in Petri dishes with moistened filter paper.

This study aimed to reduce the information gap in the existing literature regarding the effects of excess of water during bermudagrass germination and early stage of growth. Germination of five bermudagrass cultivars and subsequent seedling growth of four of them under different water floating/submersion periods were investigated.

\section{Materials and methods}

A growth chamber and a greenhouse experiment were carried out at the Agricultural Experimental Farm of Padova University in Legnaro, Italy (lat. $45^{\circ} 20^{\prime} \mathrm{N}$, long. $11^{\circ} 57^{\prime} \mathrm{E}$, elevation $8 \mathrm{~m}$ ).

\section{Laboratory experiment}

In 2016, five seeded bermudagrass cultivars among the most widespread in the Italian turf market ('Jackpot', 'La Paloma', 'Transcontinental', 'Yukon', and 'Sunbird') were tested in a growth chamber for seed germination under different water submersion conditions. Treatments compared were: a) 0 (control), 2, 4, and 6 days submersion with seeds floating; b) 0 (control), 2, 4, and 6 days full submersion with seeds kept submerged using a plastic net. Unhulled seeds, previously stored at a temperature of $5^{\circ} \mathrm{C}$ for six months to interrupt possible dormancy, were submerged for different periods in plastic containers filled with deionized water. Subsequently, 100 seeds of each cultivar were placed on filter paper in $10-\mathrm{cm}$ diameter Petri dishes. The filter paper was moistened with deionized water. No methods to increase germination, as indicated by the International Seed Testing Association, were used (ISTA, 2013). Seeds were tested in a $\mathrm{KW}$ incubator under alternating temperature $30 / 20^{\circ} \mathrm{C}$ and 14/10 h (light/dark) photoperiod. Petri dishes were randomly placed in the incubator with five replications. The numbers of germinated seeds (primary root protrusion visible) were counted three times a week for a period of 40 days from seeding, that is about twice the period of 21 days provided by the International Seed Testing Association (2013) and the final cumulative germination proportion (FCGP) was calculated. According to Munshaw seed vigour was not considered (Munshaw et al., 2014).

\section{Greenhouse experiment}

A greenhouse experiment was conducted during spring 2017 using the same bermudagrass cultivars and the same seed lots used for the growth chamber experiment. The seeds were placed in plastic trays with a mix of soil/sand to test seedling growth under different water submersion conditions: no submersion (control), 2, 4, 6 and 8-days submersion. Before the experiment, seeds were stored at a temperature of $5^{\circ} \mathrm{C}$ for six months to interrupt dormancy. Greenhouse air temperatures were monitored with a digital datalogger Onset HOBO Pendant temp UA-001-64' between 11.1 and $32.1^{\circ} \mathrm{C}$ with a mean of $22.4^{\circ} \mathrm{C}$. Each tray contained a $3-\mathrm{cm}$ bed of expanded clay separated by a nonwoven fabric towel from a $3-\mathrm{cm}$ layer of a soil-sand mix $(70 \%$ and $30 \% \mathrm{v} / \mathrm{v})$. The soil was a sandy loam containing $60.8 \%$ sand, $28.9 \%$ silt, and $10.3 \%$ clay, with $\mathrm{pH} 8.3$, organic matter $21 \%$, C-to-N ratio of 12.2, Olsen $\mathrm{P}$ content of $4.2 \mathrm{mg} \mathrm{kg}^{-1} \mathrm{P}$, and exchangeable $\mathrm{K}$ content of $86 \mathrm{mg} \mathrm{kg}^{-1}$, and it was previously oven-sterilized at $105^{\circ} \mathrm{C}$ for $48 \mathrm{~h}$. Two hundred uncoated seeds were distributed in each tray on 17 March 2017 and covered with 1-2 mm of sand. Plastic trays were arranged in a randomized complete block design with four replicates. Before distribution of seed, the top $3 \mathrm{~cm}$ of soil was moistened by automatic sprinkler irrigation. After seeds distribution, trays were regularly irrigated until the beginning of the submersion, while trays of 'control' were irrigated for the entire experimental period. The number of seedlings that emerged were recorded every other day. The cultivar La Paloma showed very low germination and was excluded and not submerged. Submersion treatment started when about $40 \%$ of seeds were emerged (Figure 1), which corresponds to the peak of the 


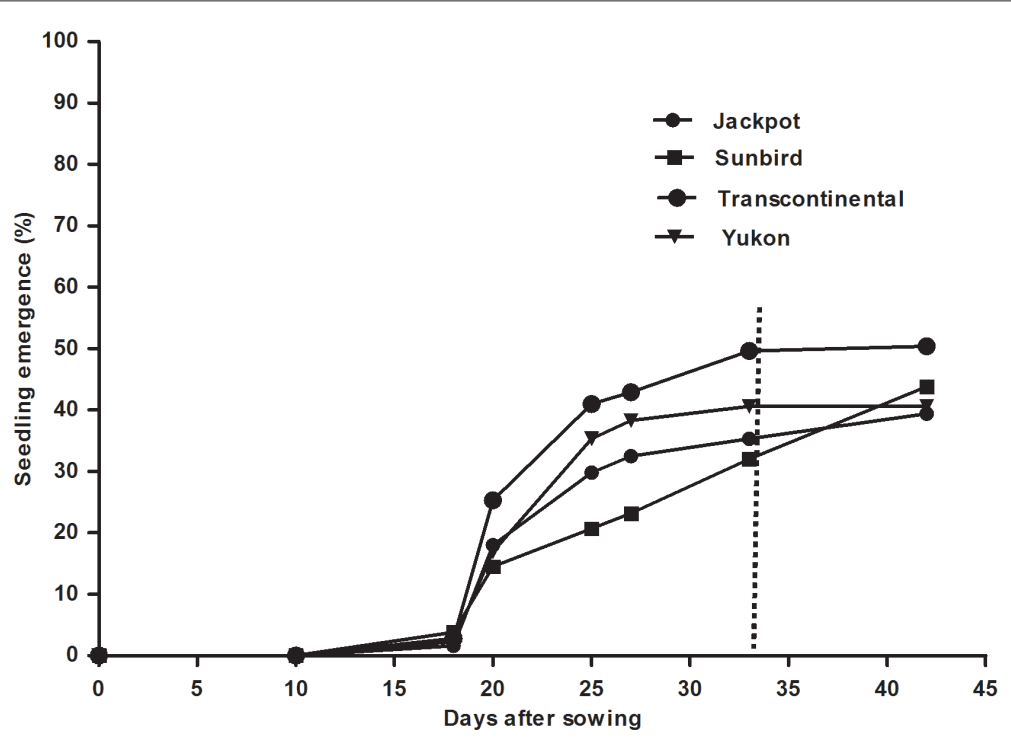

FIGURE 1. Cumulative seedling emergence curves of four bermudagrass cultivars under no submersion (Control). The vertical dotted line indicates the last count (33 days after seeding) before the beginning of submersion (Greenhouse experiment).

FCGP curves. The submersion occurred when average seedlings emergence was about $40 \%$ (Figure 1). At this level, the emergence was at the peak, or it had peaked and was gradually slowing down (Bewley et al., 2013). This level represented around $90 \%$ of maximum seedling emergence reached by the control after the submersion period. Flooding treatment consisted of complete submersion of seedlings (1-2 cm of water above the soil surface). For each cultivar, the comparison with the control was carried out by matching the end of the immersion of the four treatments $(2,4,6$, and 8 days $)$ on the same day. The four submersions then progressively occurred to 2 days away from one another. The number of growing seedlings was recorded weekly from April 4 to April 28, and the number of yellow seedling leaves per seedling was also recorded on April 28.

\section{Statistical analysis}

The FCGP and the proportion of not-germinated seeds of the laboratory experiment were analysed using a Generalised Linear Model with binomial error and logit link; a dispersion parameter was added to account for overdispersion (quasi binomial model). Submersion treatment (different submersion types and durations), cultivar and the interaction 'submersion $\times$ cultivar' were added as fixed effects. The significance of fixed effects was tested using Wald $\mathrm{F}$ tests. Back transformed FCGP were derived and are reported in Table 1.

In the greenhouse experiment, the cultivar La Paloma showed very low germination under all the treatments, and it was not included in the statistical analysis. Two variables were recorded after 2, 4, 6, and 8-days submersion, i.e., the FCGP of seedlings surviving submersion and the proportion of yellow seedlings. Both variables were analysed using a Generalised Linear Model with binomial error and logit link; a dispersion parameter was added to account for overdispersion (quasi binomial model). Block, submersion, cultivar and the interaction 'submersion $\times$ cultivar' were added as fixed effects. The significance of fixed effects was tested using Wald F tests. Back transformed FCGP were derived and are reported in Tables 2 and 3.

All statistical data analysis was performed using the $\mathrm{R}$ statistical environment (R Core Team, R 3.5.0, 2018) together with the package "emmeans" (Lenth et al., 2018).

\section{Results and discussion}

\section{Laboratory experiment}

The FCGP of the five cultivars tested in the growth chamber is reported in Table 1. The FCGP of the control ranged between the proportion of germinated seeds of 0.444 and 0.814 and it is expressed as the result of the fraction of germinated seeds on the total equal to 1.0. Except for 'La Paloma', the seeds germinated proportion of the control was near $0.70(70 \%)$ that is the minimum threshold for the seed market of this species in the EU (The Council of the European Economic Community, 1966).

The analysis of deviance for generalized linear model fits on FCGP showed a significant 'treatment $\times$ cultivar' interaction $\left(\mathrm{P}=2.042 \mathrm{e}^{-15}\right)$. The main effects of 'treatment' and 'cultivar' were also significant $\left(\mathrm{P}=4.794 \mathrm{e}^{-09}\right.$ and $\mathrm{P}<2.2 \mathrm{e}^{-16}$, respectively). The five cultivars displayed a different response to both submersion and floating treatments, especially for the most prolonged duration ( 6 days). In the absence of submersion or floating (control) 'La Paloma' revealed higher FCGP than under 4 and 6 days of submergence or 6 days of flooding (Figure 2), while 'Yukon' showed a significant decrease in FCGP after 6 days of floating. This cultivar also revealed a significant reduction in FCGP after 4 and 6 days of continuous submersion (Figure 3). Furthermore, 'Yukon' showed the highest FCGP under 2 days' submersion. This result could be due to a better imbibition of seed under limited submersion conditions, compared with no submersion or prolonged submersion.

The cultivars Jackpot, Sunbird and Transcontinental, did not exhibit any significant difference among treatments (Table 1). The difference in FCGP between floating and immersion (Figures 2 and 3) was probably due to the increase of seed 'weight density' by water imbibition under floating, allowing to complete the absorption phase. Immersion is conversely characterized by an initial phase of faster imbibition followed by a progressive decrease of oxygen availability which leads to lower germination (Bewley et al., 2013). 

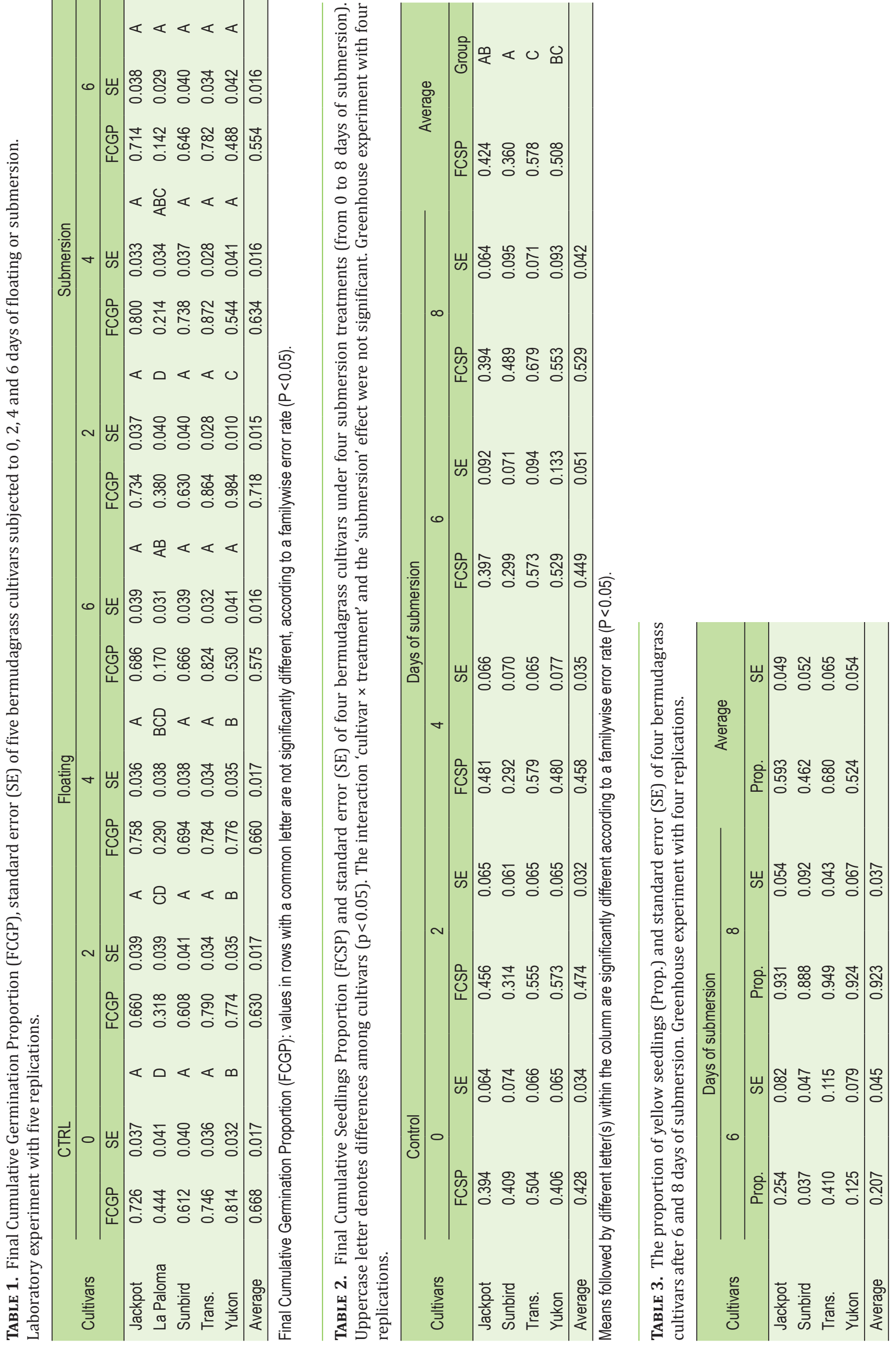


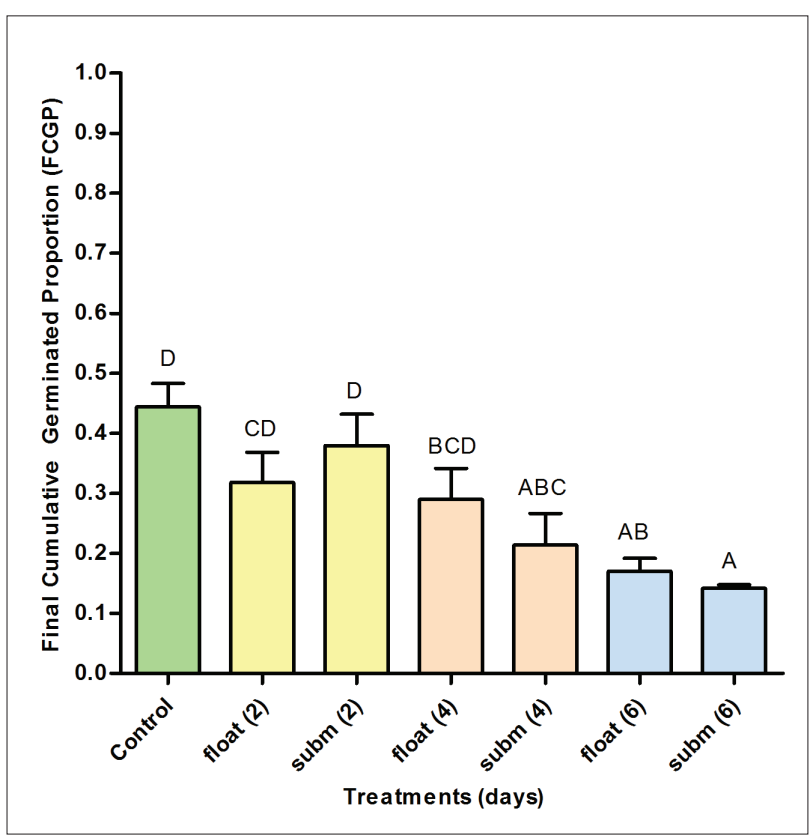

Figure 2. Final Cumulative Germination Proportion of 'La Paloma' bermudagrass at $0,2,4$ and 6 days of floating and submersion. Bars with no letters in common are significantly different $(\mathrm{p}<0.05)$. Vertical bars represent the standard error (Laboratory experiment).

A significant difference between floating and submerged occurred only for a short initial period when oxygen availability was higher, and seed imbibition was in progress. These results are in agreement with Moriaga (1926) who demonstrated in a laboratory study (in 'bottles') that bermudagrass is tolerant to submersion conditions and germination level under full submersion can be higher than germination in 'Petri dishes' (seeds tested for 42 days). As reported by Bewley et al. (2013), seed imbibition increases its fresh weight from 40 to $50 \%$, and a wholly soaked seed can reach a percentage of moisture between 75 and $100 \%$.

\section{Greenhouse experiment}

Results of the analysis of deviance for the final cumulative seedlings proportion (FCSP) showed significant differences only for the effect of the cultivar $(\mathrm{P}=0.00016)$, while the interaction 'cultivar $\times$ treatment' and the submersion effect were not significant ( $\mathrm{P}=0.67$ and 0.44 , respectively). The observed FCSP and the significance among cultivars are reported in Table 2.

Transcontinental displayed a significantly higher cumulative seedlings proportion (0.58) than 'Jackpot' (0.42) and 'Sunbird' (0.36), while 'Sunbird' (0.36) showed a cumulative seedlings proportion significantly lower than 'Yukon' (0.51) and 'Transcontinental' (0.58). Statistical analysis did not reveal significant differences among the five submersion treatments, suggesting that bermudagrass seedlings can easily withstand prolonged periods of waterlogging.

Unlike germination, the FCSP showed differences only among cultivars. By germination, bermudagrass shifts from a heterotrophic to the autotrophic organism, where leaflets and roots also play an essential role in response to submersion. Results obtained are in agreement with previous researches on bermudagrass, indicating that bermudagrass seedlings have a high tolerance to water submersion (Ashraf and Yasmin, 1991; Springer et al., 2014; Tan et al., 2010).

Regarding leaf yellowing (symptoms of hypoxia) results

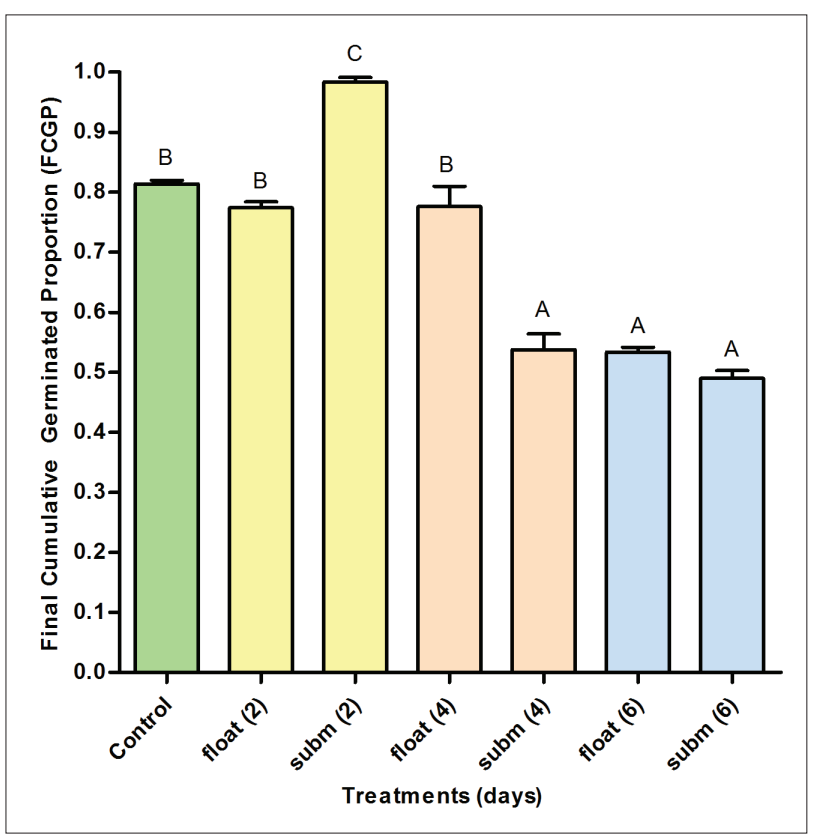

FIGURE 3. Laboratory: Final Cumulative Germination Proportion of 'Yukon' bermudagrass at respectively 0, 2, 4 and 6 days of floating and submersion. Bars with no letters in common are significantly different $(\mathrm{p}<0.05)$. Vertical bars represent the standard error (Laboratory experiment).

of statistical analysis for flooding, treatments revealed a significant 'treatment $\times$ cultivar' interaction $\left(\mathrm{P}=5.64 \mathrm{e}^{-07}\right)$. No significant differences between 2 and 4 days submersion were observed. In comparison, water submersion for 6 and 8 days resulted in a significant increase in the number of yellow seedlings $\left(\mathrm{P}=1.57 \mathrm{e}^{-06}\right)$, with no differences among cultivars (Table 3). Moreover, the submersion of 8 days showed a significant increase in the number of seedlings affected by leaf yellowing in comparison with 6 days of submersion. Thus, 6 days of submersion indicates the beginning of visible suffering on bermudagrass seedlings. This result is in agreement with previous studies reporting bermudagrass moderately tolerant of flooding (Ashraf and Yasmin, 1991; Tan et al., 2010). Studies carried out on sugarcane (Saccharum officinarum L.) that belongs to the same botanical family of bermudagrass, confirmed that submersion causes leaf yellowing (Gomathi et al., 2015) as a consequence of depletion of chlorophyll content (Gomathi et al., 2015). Another study conducted by Ye et al. (2015) reported that submersion negatively affects photosynthesis and redox-related pathways of bermudagrass.

\section{Conclusion}

Bermudagrass seeds and seedlings denoted a short-term resilience to flooding. The seeds of the five tested bermudagrass cultivars showed a moderate tolerance to floating/ submersion during germination even though differences among cultivars were found. In particular, 'Jackpot', 'Sunbird', and 'Transcontinental' were the most tolerant. Future breeding programs should take into account the bermudagrass genetic variations for the selection of cultivars more tolerant of these stresses. Ultimately, six to eight days of full submersion represents the threshold for symptoms of hypoxia with yellowing of the seedlings basal leaves. We can, therefore, state that it is possible seeding bermudagrass without fear for heavy rain events. However, the seed/seedling environment interactions remain mostly unknown. Thus, a field experiment could be necessary to confirm these results. 


\section{References}

Ashraf, M., and Yasmin, H. (1991). Differential waterlogging tolerance in three grasses of contrasting habitats: Aeluropus lagopoides (L.) Trin., Cynodon dactylon (L.) Pers. and Leptochloa fusca (L.) Kunth. Environm. Experim. Botany 31, 437-445. https:// doi.org/10.1016/0098-8472(91)90042-M.

Bailey-Serres, J., Lee, S.C., and Brinton, E. (2012). Waterproofing crops: effective flooding survival strategies. Plant Physiol. 160, 1698-1709 https://doi.org/10.1104/pp.112.208173.

Batzli, J.M., and Dawson, J.O. (1997). Physiological and morphological responses of red alder and sitka alder to flooding. Physiol. Plant. 99, 653-663. https://doi.org/10.1111/j.1399-3054.1997.tb05369.x.

Bewley, J.D., Bradford, K., Hilhorst, H.W.M., and Nonogaki, H. (2013). Seeds: Physiology of Development, Germination and Dormancy, $3^{\text {rd }}$ edn. (New York, USA: Springer). https://doi.org/10.1007/978-14614-4693-4.

Bradford, K.J. (2002). Applications of hydrothermal time to quantifying and modeling seed germination and dormancy. Weed Sci. 50, 248260. https://doi.org/10.1614/0043-1745(2002)050[0248:AOHTTQ] 2.0.CO;2.

Casnoff, D.M. (1989). Leaf blade stomatal densities of ten warmseason perennial grasses and their evapotranspiration rates. Proc. Sixth Int. Turfgrass Research Conference, p. 129-131.

Chesworth, W. (2008). Encyclopedia of Soil Science (Dordrecht, The Netherlands: Springer).

De Luca, A., Volterrani, M., Gaetani, M., Grossi, N., Croce, P., Mocioni, M., and Lulli, F. (2008). Warm Season Turfgrass Adaptation in Europe North of the $45^{\circ}$ Parallel, p. 7. https://doi.org/10.1007/978-1-40203995-9.

Desiato, F., Fioravanti, G., Fraschetti, P., Perconti, W., and Piervitali, E. (2015). Il clima futuro in Italia: analisi delle proiezioni dei modelli regionali (The future climate in Italy: analysis of the regional model projections). Italian Nat. Inst. Environm. Proj. Res. (ISPRA) (Rome, Italy), 58.

Desiato, F., Fioravanti, G., Fraschetti, P., Perconti, W., Piervitali, E., and Pavan, V. (2019). Gli indicatori del clima in Italia nel 2018 (Climate indicators in Italy in 2018). Italian Nat. Inst. Environm. Proj. Res. (ISPRA) (Rome, Italy), 8.

Gomathi, R., Gururaja Rao, P.N., Chandran, K., and Selvi, A. (2015) Adaptive responses of sugarcane to waterlogging stress: An overview. Sugar Techn. 17, 325-338. https://doi.org/10.1007/s12355-0140319-0.

Huang, B., Beard, J.B., and Kenna, M.P. (2008). Turfgrass water requirements and factors affecting water usage Council Agr. Sci. Technol. Spec. Publ. No. 27.

Huang, S., Jiang, S., Junsong, L., Chen, M., and Shi, Y. (2019). Current knowledge of bermudagrass responses to abiotic stresses. Breeding Sci. 69(2), 215-226 https://doi.org/10.1270/jsbbs.18164.

IPCC (2014). Climate Change 2014 Synthesis Report (Intergovernmental Panel on Climate Change).

ISTA (2013). International Rules for Seed Testing (Zurich: Int. Seed Testing Association).

Jackson, M.B., and Colmer, T.D. (2005). Response and adaptation by plants to flooding stress. Ann. Bot. 96, 501-505. https://doi. org/10.1093/aob/mci205.

Lenth, R., Singmann, H., Love, J., Buerkner, P., and Herve, M. (2018). emmeans: Estimated Marginal Means, aka Least-Squares Means.

Letey, L., Morgan, W.C., Richards, S.J., and Valoras, N. (1966). Physical soil amendments, soil compaction, irrigation, and wetting agents in turfgrass management. III. Effects on oxygen diffusion rate and root growth 1. Agron. J. 58, 531-535. https://doi.org/10.2134/agronj19 $66.00021962005800050024 x$.

Macolino, S., Schiavon, M., Leinauer, B., and Ziliotto, U. (2016). Seasonal changes in carbohydrate and protein content of seeded Bermudagrasses and their effect on spring green-up. J. Agron. Crop Sci. 202, 151-160. https://doi.org/10.1111/jac.12135.

Medri, S., Venturini, S., and Castellari, S. (2013). Overview of Key Climate Change Impacts, Vulnerabilities and Adaptation Action in Italy (Rochester, NY: Social Science Research Network). https://doi. org/10.2139/ssrn.2317832.

Morinaga, T. (1926). Germination of seeds under water. Am. J. Botany 13, 126-140. https://doi.org/10.1002/j.1537-2197.1926. tb05873.x.

Munshaw, G.C., Layton, J.M., Stewart, B.R., Philley, H.W., Beasley, J.S., and Lemus, R.W. (2014). The germination responses of five Bermudagrass cultivars to seedcoating and temperature. HortScience 49, 1225-1229. https://doi.org/10.21273/HORTSCI.49.9.1225.

Neira, J., Ortiz, M., Morales, L., and Acevedo, E. (2015). Oxygen diffusion in soils: Understanding the factors and processes needed for modeling. Chilean J. Agric. Res. 75, 35-44. https://doi. org/10.4067/S0718-58392015000300005.

Parent, C., Nicolas, C., Audrey, B., Crèvecoeur, M., and Dat, J. (2008). An overview of plant responses to soil waterlogging. Plant Stress 2(1), 20-27.

Pedersen, O., Colmer, T.D., and Sand-Jensen, K. (2013). Underwater photosynthesis of submerged plants - Recent advances and methods. Front. Plant Sci. 4. https://doi.org/10.3389/fpls.2013.00140.

Puhalla, J., Krans, J., and Goatley, M. (1999). Sports Fields: A Manual for Design, Construction and Maintenance (John Wiley \& Sons).

R Core Team (2018). R 3.5.0. R: A language and environment for statistical computing. https://www.r-project.org/.

Rimi, F., Macolino, S., Leinauer, B., and Ziliotto, U. (2011). Greenup of seeded Bermudagrass cultivars as influenced by spring scalping. HortTechnology 21, 230-235. https://doi.org/10.21273/ HORTTECH.21.2.230.

Rimi, F., Macolino, S., Richardson, M.D., Karcher, D.E., and Leinauer, B. (2013a). Influence of three nitrogen fertilization schedules on Bermudagrass and seashore Paspalum: I. Spring green-up and fall color retention. Crop Sci. 53, 1161-1167. https://doi.org/10.2135/ cropsci2012.09.0562.

Rimi, F., Macolino, S., Richardson, M.D., Karcher, D.E., and Leinauer, B. (2013b). Influence of three nitrogen fertilization schedules on Bermudagrass and seashore Paspalum: II. Carbohydrates and crude protein in stolons. Crop Sci. 53, 1168-1178. https://doi. org/10.2135/cropsci2012.09.0564.

Severmutlu, S., Mutlu, N., Shearman, R.C., Gurbuz, E., Gulsen, O., Hocagil, M., Karaguzel, O., Heng-Moss, T., Riordan, T.P., and Gaussoin, R.E. (2011). Establishment and turf qualities of warm-season turfgrasses in the Mediterranean region. HortTechnology 21, 67-81. https://doi.org/10.21273/HORTTECH.21.1.67.

Springer, R., Eudoxie, G., and Gouveia, G. (2014). Comparative evaluation of common savannah grass on a range of soils subjected to different stresses. II: Root zone physical condition. Agronomy 4, 124-143. https://doi.org/10.3390/agronomy4010124.

Striker, G. (2012). Flooding Stress on Plants: Anatomical, Morphological and Physiological Responses. (Rijeka, Croatia: InTech).

Tan, S., Zhu, M., and Zhang, Q. (2010). Physiological responses of bermudagrass (Cynodon dactylon) to submergence. Acta Physiol. Plant. 32, 133-140. https://doi.org/10.1007/s11738-009-0388-y. 
The Council of the European Economic Community (1966). Council Directive of 14 June 1966 on the marketing of fodder plant seed. Annex II. Conditions to be satisfied by the seed.

Voesenek, L., Colmer, T.D., Pierik, R., Millenaar, F.F., and Peeters, A.J.M. (2006). How plants cope with complete submergence. New Phytol. 170, 213-226. https://doi.org/10.1111/j.1469-8137.2006.01692.x.

Wherley, B., Bowman, D., Shi, W., and Rufty Jr., T. (2011). Effect of soil saturation on development and ${ }^{15} \mathrm{~N}$-nitrate uptake efficiency of two warm season grasses emerging from dormancy. J. Plant Nutr. 34, 2039-2054. https://doi.org/10.1080/01904167.2011.610489.

Ye, T., Shi, H., Wang, Y., and Chan, Z. (2015). Contrasting changes caused by drought and submergence stresses in Bermudagrass (Cynodon dactylon). Front. Plant Sci. 6. https://doi.org/10.3389/ fpls.2015.00951.

Zollo, A.L., Rillo, V., Bucchignani, E., Montesarchio, M., and Mercogliano, P. (2016). Extreme temperature and precipitation events over Italy: Assessment of high-resolution simulations with COSMO-CLM and future scenarios. Int. J. Climatology 36, 987-1004. https://doi.org/10.1002/joc.4401.

Received: Nov. 19, 2019

Accepted: Apr. 6, 2020

Addresses of authors:

Maurizio Giolo ${ }^{3}$, Roberta Masin ${ }^{1}$, Stefano Macolino ${ }^{1, *}$ and Andrea Onofri ${ }^{2}$

${ }^{1}$ Department of Agronomy, Food, Natural resources, Animals, and Environment, University of Padova, Legnaro (PD), Italy

${ }^{2}$ Department of Agricultural, Food and Environmental Sciences, University of Perugia (PG), Italy

${ }^{3}$ CREA-DC, Research Centre for Plant Protection and Certification, Lonigo (VI), Italy

* Corresponding author; E-mail: stefano.macolino@unipd.it Agripolis, Viale dell'Università, 16, 35020 Legnaro (Padova), Italy, Tel.: +39 0498272834 